\title{
Markus Hertrich*
}

\section{The Costs of Implementing a Unilateral One-Sided Exchange Rate Target Zone}

DOI 10.1515/roe-2015-1006

\begin{abstract}
In the aftermath of the recent financial crisis, the central banks of small open economies such as the Swiss National Bank (SNB) implemented a unilateral one-sided exchange rate target zone vis-à-vis the euro currency to counteract deflationary pressures. Recently, the SNB abandoned its minimum exchange rate regime, arguing that after having analyzed the costs and benefits of this non-standard exchange rate policy measure, it was no longer sustainable. This paper proposes a model that allows central banks and policymakers to estimate ex-ante the costs of implementing and maintaining a unilateral onesided target zone (in terms of the expected size of foreign-exchange interventions) and to monitor these costs during the period in which it is enforced. The model also offers central banks a tool to identify the right timing for the discontinuation of a minimum exchange rate regime. An empirical application to the Swiss case shows the ex-ante estimated size of these costs and reveals that these costs might have been substantial without the abandonment of the minimum exchange rate regime, which accords with the official statements of the SNB.
\end{abstract}

Keywords: foreign-exchange interventions, foreign exchange reserves, minimum exchange rate, reflected geometric Brownian motion, target zone costs, Swiss National Bank

JEL classifications: E42, E52, E58, E63, F33, F45

\section{Introduction}

In the aftermath of the recent financial crisis that erupted in 2007/08, the central banks of small open economies (e. g., measured by the open market index of the International Chamber of Commerce (ICC Research Foundation, 2013)) such as the Czech National Bank (CNB) and the Swiss National Bank (SNB) both

\footnotetext{
*Corresponding author: Markus Hertrich, Department of Finance, University of Basel, Peter Merian-Weg 6, 4052 Basel, Switzerland; and Institute for Finance, University of Applied Sciences Northwestern Switzerland, Peter Merian-Strasse 86, 4002 Basel, Switzerland, E-mail: markus.hertrich@unibas.ch
} 
implemented a unilateral one-sided exchange rate target zone vis-à-vis the euro currency since November 7, 2013 to date and from September 6, 2011 to January 15, 2015, respectively. Before this crisis, the central banks of other small open economies such as the Swedish Riksbank from 1993 to 2002 (Humpage and Ragnartz, 2006), the Croatian National Bank in 1993 (Cottarelli and Doyle, 1999) and the Central Bank of Hong Kong from autumn 2003 up to May $2005^{1}$ had temporarily introduced a one-sided target zone to prevent the domestic currency from appreciating vis-à-vis a specific foreign currency beyond some announced minimum exchange rate level, herewith implementing a so-called strong-side commitment. Moreover, in 1978, the SNB already had temporarily implemented a one-sided target zone, when the SNB set a minimum exchange rate vis-à-vis the Deutsche mark (DEM) to impede a strengthening of the Swiss franc (CHF) beyond the level of DEM-CHF 0.80. ${ }^{2}$

Recently, a strand of literature has emerged that analyzes the credibility of the Swiss target zone vis-à-vis the euro currency in the aforementioned period of interest (Hertrich and Zimmermann, 2015) and estimates the latent spot EUR-CHF exchange rate that would have prevailed without the SNB's non-standard exchange rate policy measure (Hanke, Poulsen, and Weissensteiner (2014), Hanke, Poulsen, and Weissensteiner (2015) and Jermann (2015)). Other studies explore whether the exchange rate target model developed by KRUGMAN (1991) provides a good explanation of the Swiss currency in the period where the EUR-CHF 1.20 exchange rate floor was enforced (STUDER-SUTER and JANSSEN (2014), LERA and Sornette (2016) and Hertrich (2016)). This paper contributes to this strand of literature and proposes a model that allows central banks to estimate ex-ante the costs of implementing and maintaining a unilateral one-sided target zone (in terms of the change in the size of the domestic central bank's balance sheet due to foreign exchange interventions) and to monitor these costs during the period where it is enforced. The model also offers central banks a tool to identify the right timing for the discontinuation of a minimum exchange rate regime. The timing is relevant, since this policy may create unwanted asset price bubbles if central banks wait too long to abandon this policy. An empirical application to the Swiss case shows the ex-ante estimated size of these costs in the period

1 In 2005, Hong Kong switched to a two-sided target zone by installing a strong-side boundary for the Hong Kong dollar-U.S. dollar (USD) exchange rate, see GenkeRg and HuI (2011) or Chen, Funke, and Glanemann (2013).

2 Furthermore, the empirical results in Chen and Giovannins (1992) indicate that under the European Monetary System in the 1990s some central banks indeed were enforcing an implicit upper or lower boundary. Similarly, the Japanese monetary authorities have actively intervened in the foreign exchange market to impede appreciations of the yen vis-à-vis the USD (CHABouD and HuMPAGE, 2005) and as such have created a temporary lower boundary. 
where the minimum EUR-CHF exchange rate regime was in place and reveals that these costs might have been substantial without the abandonment of the minimum exchange rate regime, which accords with the official statements of the SNB.

The paper is structured as follows: Section 2 shows how the exchange rate can be modeled under a strong-side commitment when the domestic central bank enforces a minimum exchange rate on a continuous basis. In Section 3, it is shown how the costs of implementing and maintaining a unilateral one-sided target zone (or strong-side commitment) can be estimated ex-ante and during the period where it is enforced. As a robustness check, Section 4 considers an alternative way of modeling these costs, while Section 5 analyzes the actual costs of the SNB's exchange rate policy regime vis-à-vis the euro currency from September 6, 2011 to January 15, 2015 and discusses the timing of the SNB's decision to abandon this policy. Section 6 summarizes the main findings of the paper.

\section{The exchange rate dynamics in a one-sided target zone}

\subsection{Free floating exchange rate regime}

Assume that before the implementation of the strong-side commitment the spot exchange rate $F_{t}$ (quoted as the number of units of domestic currency required to buy one unit of foreign currency as of time $t$, see, for instance, REISwich and Wystup (2010)) follows a geometric Brownian motion (GBM) process (which is a commonly used assumption in finance, see Glasserman (2004), Wystup (2010a), Musiela and RutKowski (2009) or GEMAN (2015), among others) in a free floating exchange rate system with drift coefficient $\mu$ and diffusion coefficient $\sigma$, respectively:

$$
d F_{t}=\mu F_{t} d t+\sigma F_{t} d W_{t}
$$

where $d W_{t}$ denotes the increment of a standard Wiener process. By applying Ito's lemma to $\ln \left(F_{t}\right)$, we find that

$$
f_{t} \equiv d \ln \left(F_{t}\right)=\left(\mu-\frac{\sigma^{2}}{2}\right) d t+\sigma d W_{t} .
$$

The exchange rate is a martingale if the drift coefficient $\mu$ is replaced by 


$$
\mu^{\star}=r-r^{f}
$$

where $r$ and $r^{f}$ are the annual, continuously compounded risk-free interest rates in the domestic and foreign currency, respectively.

\subsection{Minimum exchange rate regime}

Inspired by the recent non-standard exchange rate policy of the SNB that enforced a minimum EUR-CHF 1.20 exchange rate from September 6, 2011 to January 15, 2015, this paper focuses on a unilateral (in the following, this term will be omitted for the sake of simplicity) one-sided target zone for the exchange rate $F_{t}$ subject to a lower boundary $b$, whereby a central bank intervenes in the spot market with unsterilized foreign exchange transactions by buying a specific foreign currency ${ }^{3}$ (e.g., the euro currency in the case of the SNB) to maintain a minimum exchange rate $b$ (which will be called "floor" in the following), whenever necessary. As a consequence, the observed spot exchange rate under the minimum exchange rate regime $S_{t}$ will be equal to or larger than the latent (or now shadow) exchange rate $F_{t}$ (i. e., the exchange rate that would prevail without the interventions of the domestic central bank). The observed exchange rate $S_{t}$ then equals:

$$
S_{t}=F_{t} \cdot \max \left\{1, \max _{0 \leq s \leq t} b / F_{s}\right\}, \text { for } \leq t \leq T,
$$

where $T$ denotes the finite lifetime (in years) of the minimum exchange rate regime.

According to Equation (4), as long as $F_{t}>b$, the spot exchange rate $S_{t}$ is equal to the latent exchange rate $F_{t}$ (and therefore $S_{0}=F_{0}$ ), as no interventions by the domestic central bank have changed the domestic monetary base yet. However, once the latent exchange rate $F_{t}$ falls below the floor level b (e. g., if $F_{0}$ $<b$, then $S_{0}$ equals $b$ ), a gap emerges between $F_{t}$ and the observed exchange rate $S_{\mathrm{t}}$, reflecting the interventions of the domestic central bank that drive a wedge between both exchange rates (since the unsterilized interventions change the domestic monetary base). Moreover, if after these interventions the latent exchange rate increases again (i.e., by exogenous factors), these exchange

3 Given that before the SNB discontinued the minimum exchange rate, other alternatives to a removal of the minimum EUR-CHF 1.20 exchange rate were discussed as well, most notably a pegging of the Swiss franc to a currency basket (see, e. g., BALTENSPERGER (2015) and Bernholz (2015)), the domestic central bank may alternatively peg its currency to a currency basket to enforce a minimum exchange rate. 
rate changes will be reflected one-to-one in the observed spot exchange rate St. Consequently, whenever $S_{t}>b$, the risk-neutralized drift rate of $S_{t}$ and the drift rate $\mu^{*}$ of $F_{t}$ will be identical.

Scaling the stochastic process $S_{t}$ in Equation (4) by the floor $b$ and taking logs, the resulting stochastic process $\left\{\ln \left(S_{t} / b\right)\right\}$ results from the (scaled) exchange rate process $\left\{\ln \left(F_{t} / b\right)\right\}$ in a free-floating exchange rate regime by introducing a reflecting barrier at zero. ${ }^{4}$ After simple algebra, it can be shown that the stochastic process $\left\{\ln \left(S_{t} / b\right)\right\}$ is a representation of a reflected (or regulated) BM started at $\left\{\ln \left(S_{0} / b\right)\right\}$ (Graversen and Shiryaev (2000) and Ko, Shiu, and WEI (2010)), which accords with the foreign exchange rate dynamics implied by the Krugman (1991)-type models (Hui, Lo, and Fong (2015) and Lo ET AL. (2015)).

Consequently and in accordance with the target zone model developed by VEESTRAETEN (2013), the observed exchange rate can be modeled as a reflected GBM (RGBM):

$$
d S_{t}=\left(r-r^{f}\right) \cdot S_{t} d t+\sigma S_{t} d W_{t}+S_{t} d L_{t},
$$

where the process $L_{t}$ is the so-called reflection function in Sковокнор (1961) and represents the cumulative increase in the exchange rate effected by the domestic central bank up to time $t$. Given the setup in the empirical analysis in Section 5, $L_{t}$ is a continuous, non-decreasing process with $L_{0}=0$ and increases only when $S_{t}$ hits the lower barrier $b$ (see, e. g., HARRISON (1985)). In that case, reflection takes place instantaneously. This reflection mechanism ensures that the exchange rate does not spend finite time on the barrier, such that no situation can arise in which the exchange rate could only move in one direction, hereby enabling risk-less arbitrage gains (see, e. g., INGERSOLL JR. (1987) on page 270 or BERGMAN (1996) for more details about this statement) and thereby attracting speculators. For more details on the reflection mechanism and its implications for option pricing, the interested reader is referred to VEESTRAETEN (2008).

Let $S_{0}$ denote the exchange rate that is observed in the market just after announcing the introduction of a lower floor level for the exchange rate $F_{t}$. Assuming that the domestic currency is (potentially) overvalued vis-à-vis the involved foreign currency prior to the announcement of the floor, ${ }^{5}$ which induces the domestic central bank to introduce a nonstandard exchange rate policy measure in the form of a minimum exchange rate that either equals or is below the "fair" (or fundamental) equilibrium exchange rate at inception, it is

4 See, e. g., Flood and Marion (1994), Gerber and Pafumi (2000), Ko, Shiu, and Wei (2010), Veestraeten (2013), Hertrich and Zimmermann (2015) and Neuman and Schied (2015) for a similar approach applied to foreign exchange markets or in the context of investment funds.

5 Which accords with the official statements of the SNB. 
assumed that the spot exchange rate "jumps" to $S_{0}=F_{0}>F_{-1}$ just after officially announcing the introduction of the floor, which can be motivated by the signalling channel (see, e. g., Dominguez (1998) and Sarno and Taylor (2001)). ${ }^{6}$ Hence, assuming that the latent exchange rate $F_{t}$ is the equilibrium exchange rate for $t \geq 0$ that would prevail without the enforcement of the floor (which accords with the assumption in Hanke, Poulsen, and Weissensteiner (2014), Hanke, Poulsen, and Weissensteiner (2015) and JERMANN (2015)), under the strong-side commitment $S_{t} \geq$ $F_{t}$ for $t \geq 0$, whereby the domestic currency will be either "fairly" priced or undervalued (due to the possibility of interventions by the domestic central bank) with respect to the foreign currency compared to the situation in a freefloating exchange rate regime.

Let $p(x ; k, T), x>0$, denote the transition probability density of the RBM process $\left\{\ln \left(S_{t} / b\right)\right\}$ with the log-moneyness $k=\ln \left(S_{0} / b\right)$. Under the risk-neutral measure (Cox and Miller, 1965), this density function equals: ${ }^{7}$

$$
\begin{aligned}
p(x ; k, T)= & n\left(x ; k+\mu^{\star} \cdot T, \sigma^{2} \cdot T\right)+\left(\frac{b}{S_{0}}\right)^{\theta-1} \cdot n\left(x ;-k+\mu^{\star} \cdot T, \sigma^{2} \cdot T\right) \\
& -(\theta-1) \cdot \exp ^{(\theta-1) x} \cdot\left[1+\Phi\left(\frac{x+k+\mu^{\star} . T}{\sigma \cdot \sqrt{T}}\right)\right],
\end{aligned}
$$

with $\theta=\frac{2 \cdot \mu^{2}}{\sigma^{2}}$, where $n\left(x ; \mu, \sigma^{2}\right)$ denotes the probability density function of the normal distribution with mean $\mu$ and standard deviation $\sigma$ and $\Phi(x)$ denotes the cumulative distribution function of the standard normal distribution.

\subsection{RGBM and the Krugman target zone model}

Studer-Suter and Janssen (2014), Lera and Sornette (2016) and Hertrich (2016) analyze the suitability of the target zone model developed by KRUGMAN (1991) (which is based on the assumption that the fundamental variable follows a reflected GBM) in describing the EUR-CHF exchange rate dynamics in the period of interest. Their results support the main empirical implications (see Svensson

\footnotetext{
6 Assuming that the announcement of the floor is interpreted as the "fully credible" willingness of the domestic central bank to not tolerate an overvaluation of the domestic currency anymore and to actively intervene in the FX market with unsterilized transactions (i. e., by affecting the current or future fundamentals), whereby initially the spot exchange rate $S_{O}$ equals the market's perceived "new" fundamental exchange rate. Notice that the SNB indeed stopped sterilizing interventions in the indicated period of interest. Alternatively, $F_{O}$ can be set equal to $F_{-1}$, which would give a proxy for the maximum costs of implementing a one-sided target zone in the described setting. For more details on this statement, see the last paragraph in Section 3.

7 The transition probability density $p(x ; k, T)$ corresponds to Equation (2.4) in GeRBER and PAFUMI (2000), Equation (2.5) in Ko, Shiu, and Wei (2010) and Equation (5) in Veestraeten (2008).
} 
(1992a)) that the Krugman model predicts. Hence, an exchange rate model based on the Krugman framework is a natural step. Moreover, the exchange rate dynamics that have been proposed in Subsection 2.2 can also be related to the target zone model developed by KRUGMAn (1991): In the KRUGMAN (1991) target zone model the natural logarithm of the exchange rate $s_{t} \equiv \ln \left(S_{t}\right)$ depends linearly on current macroeconomic fundamentals (i. e., on fundamental determinants of the exchange rate, such as the domestic output, both the domestic and foreign money supply, as well as the foreign interest rate and the foreign price level (Svensson, 1992a)) and expectations of future values of the exchange rate. As proposed in VeESTRAETEN (2000), $s_{\mathrm{t}}$ can be related to the log of the (aggregated) fundamental of the exchange rate, which in KRUGMAN (1991) can be modeled as a RBM (Froот and OBstFeld, 1991). Specifically, if the interest rate semi-elasticity of money demand $\alpha$ in KRUGMAN (1991) is set equal to zero, the log-exchange rate $s_{\mathrm{t}}$ will equal the macroeconomic fundamental. Hence, in this case and assuming that uncovered interest rate parity holds, the drift coefficient of both the exchange rate and the fundamental should be equal to the interest differential $r-r^{f}\left(=\mu^{\star}\right.$ in this paper).

Moreover, as shown in FLood, Rose, and MathiEson (1991), the aforementioned interest rate semielasticity of money demand $\alpha$ can be estimated by running the following regression:

$$
\Delta s_{t}=\psi+\alpha\left[\Delta r_{t}-\Delta r_{t}^{f}\right]+\eta_{t},
$$

Using the data described in Subsection 5.1, the estimated semi-elasticity $\hat{\alpha}$ is statistically insignificant for the EUR-CHF FX rate in the period of interest (see Table A.1 in the Appendix A), whereby the assumption of a RGBM for $S_{t}$ can be related to the assumption of a RGBM for the fundamental in the Krugman target zone model. In addition, according to Hur, Lo, and FonG (2015) and Lo et al. (2015) the assumption of a RGBM for the fundamental implies a RGBM for the corresponding exchange rate.

\section{The costs of implementing a one-sided target zone}

Assume that the central bank of the domestic country has a finite lifetime $T$ for the strong-side commitment in mind that is, however, not publicly announced when introducing a one-sided target zone (or an unknown maturity that is constant, as in Hanke, Poulsen, and Weissensteiner (2015)). Let $V\left(S_{0}, T\right)$ denote the costs (as of time $t=0$ ) per unit of foreign currency of implementing a strong- 
side commitment for a lifetime $T$, in the sense of the extra amount of foreign currency (measured in units of the domestic currency) that a central bank has to buy due to its commitment to a publicly announced intervention level $\mathrm{b}$ for the previously free-floating exchange rate $F_{t}$. Hence, the unit cost $V\left(S_{0}, T\right)$ can be modeled as the difference between the discounted expected value of holding one unit of foreign currency both under the strong-side commitment and in a free-floating exchange rate system $\left(S_{T}-F_{T}\right)$, measured in units of the domestic currency, as the "upgraded" spot exchange rate $S_{t}$ is the result of the (expected) FX interventions by the domestic central bank in order to maintain a strong-side commitment for $T$ years, buying just enough foreign currency at the minimum exchange rate, whenever necessary, so that $S_{t}$ does not fall below $b$ :

$$
\begin{aligned}
V\left(S_{0}, T\right) & =V\left(F_{0}, T\right)=\exp ^{\left(r^{f}-r\right) T}\left[\mathrm{E}^{Q^{R G B M}}\left(S_{T}\right)-\mathrm{E}^{Q^{G B M}}\left(F_{T}\right)\right], \\
& =\exp ^{\left(r^{f}-r\right) T} \mathrm{E}^{\mathrm{Q}^{R G B M}}\left(S_{T}\right)-F_{0},
\end{aligned}
$$

with $F_{0}=S_{0}$ and where the discounted expected values $\left\{\exp ^{\left(r^{f}-r\right) T}\left[\mathrm{E}^{Q}(\cdot)\right]\right\}$ are calculated under the corresponding risk-neutral measure $Q$ with respect to the parameters $\mu^{\star}$ and $\sigma^{8}{ }^{8}$ The costs therefore reflect the FX interventions that are required to maintain the exchange rate above the targeted floor level, given the current spot exchange rate. In the following, this model will be denoted by "model 1".

Alternatively, the costs can be interpreted as the gap (or misalignment) between the exchange rate that the domestic central bank regards as the fundamental value of its currency vis-à-vis a specific currency under a minimum exchange rate regime and the free float spot exchange rate $F_{0}$, whereby the costs $V\left(S_{O}, T\right)$ equal zero, whenever both the market's and the central bank's view coincide. According to this interpretation, $\mathrm{V}\left(S_{O}, T\right) / S_{O}$ reflects the required depreciation that is necessary to move the spot market FX rate towards the fundamental value that the domestic central bank considers as "fair" (see Section 5 for more details).

Plugging the transition probability density $p(x ; k, T)$ into Equation (8) and following the steps in Gerber and PAFumi (2000) or Ko, Shiu, and WeI (2010), using the interest parity condition for $S_{T}$ and the integrals in Appendix B, the following costs (as of time $t=0$ ) of maintaining a minimum exchange rate are obtained:

8 Notice that uncovered interest parity has been applied in Equation (8), which is a standard assumption in the target zone literature (see, e.g., the credibility tests of target zones by Svensson (1991) and BerTola and Svensson (1993) that rely on this parity or the theoretical work on the foreign exchange risk premium in target zone models (Svensson, 1992b)) and is in line with the results documented in KUgLER and WedER (2009) for the EUR-CHF exchange rate. 


$$
\begin{aligned}
V\left(S_{0}, T\right)= & b \exp ^{\left(r^{f}-r\right) T}\left(1-\frac{1}{\theta}\right) \Phi\left(\frac{\ln \left(b / S_{0}\right)-\left[\mu^{\star}-\sigma^{2} / 2\right] T}{\sigma \sqrt{T}}\right) \\
& +\frac{b}{\theta}\left(\frac{b}{S_{0}}\right)^{\theta} \Phi\left(\frac{\ln \left(b / S_{0}\right)+\left[\mu^{\star}+\sigma^{2} / 2\right] T}{\sigma \sqrt{T}}\right) \\
& +S_{0} \Phi\left(\frac{\ln \left(S_{0} / b\right)+\left[\mu^{\star}+\sigma^{2} / 2\right] T}{\sigma \sqrt{T}}\right)-S_{0} .
\end{aligned}
$$

Similarly, the corresponding costs for a remaining lifetime $\tilde{T} \equiv T-t$ of the target zone equals the difference between expected exchange rate under a minimum exchange rate regime for further $\tilde{T}$ periods and the spot exchange rate (see Equations (2.11) and (5.2) in GERBER and PAFUmi (2000)):

$$
\begin{aligned}
V\left(S_{t}, \tilde{T}\right)= & b \exp ^{\left(r^{f}-r\right) \tilde{T}}\left(1-\frac{1}{\theta}\right) \Phi\left(\frac{\ln \left(b / S_{t}\right)-\left[\mu^{\star}-\sigma^{2} / 2\right] \sqrt{\tilde{T}}}{\sigma \sqrt{\tilde{T}}}\right) \\
& +\frac{b}{\theta}\left(\frac{b}{S_{t}}\right)^{\theta} \Phi\left(\frac{\ln \left(b / S_{t}\right)+\left[\mu^{\star}+\sigma^{2} / 2\right] \tilde{T}}{\sigma \sqrt{\tilde{T}}}\right) \\
& +S_{t} \Phi\left(\frac{\ln \left(S_{t} / b\right)+\left[\mu^{\star}+\sigma^{2} / 2\right] \tilde{T}}{\sigma \sqrt{\tilde{T}}}\right)-S_{t} .
\end{aligned}
$$

Notice that the costs $V\left(S_{t}, \tilde{T}\right)$ are equal to zero at $t=\mathrm{T}$.

In the following, the impact of the parameters $b$ and $T$ (i.e., the two parameters that the domestic central bank can choose freely) on the unit costs $V\left(S_{0}, T\right)$ is analyzed. Tables 1 and 2 and Figures 1 and 2 illustrate how increasing the lifetime $T$ of a one-sided target zone increases the costs of implementing a minimum exchange rate regime, irrespective of the sign of the drift rate $\mu^{\star}$. Similarly, the larger the implemented floor level $b$, the more costly it is for the domestic central bank to maintain a one-sided target zone, as it has to (potentially) intervene more often to implement the minimum exchange rate $b$.

Comparing Table 1 with Table 2 and Figure 1 with Figure 2, it becomes evident that the unit costs are larger when the drift rate $\mu^{\star}$ is negative (Table 1 and Figure 1), as in this case the foreign currency is expected to depreciate vis-àvis the domestic currency over time according to uncovered interest parity. Hence, implementing a strong-side commitment becomes ceteris paribus more "expensive", as the undervaluation (the value of $S_{t}$ vs. the value of $F_{t}$, for $0 \leq$ $t \leq T$ ) induced by the interventions of the domestic central bank increases faster over time than in the case in which the drift rate $\mu^{\star}$ is positive. Consequently, in this case the domestic central bank could increase the domestic interest rate 
Table 1: Unit costs of a one-sided target zone $\left(\mu^{\star}<0\right.$; Model 1).

\begin{tabular}{lrrrrrr}
\hline $\boldsymbol{T}$ & \multicolumn{7}{c}{} & & $\boldsymbol{b}$ \\
\cline { 2 - 7 } & $\mathbf{1 . 0 0}$ & $\mathbf{1 . 0 5}$ & $\mathbf{1 . 1 0}$ & $\mathbf{1 . 1 5}$ & $\mathbf{1 . 2 0}$ & $\mathbf{1 . 2 5}$ \\
\hline $1 \mathrm{~m}$ & 0.000 & 0.000 & 0.000 & 0.000 & 0.001 & 0.025 \\
$2 \mathrm{~m}$ & 0.000 & 0.000 & 0.000 & 0.000 & 0.005 & 0.036 \\
$3 \mathrm{~m}$ & 0.000 & 0.000 & 0.000 & 0.001 & 0.010 & 0.045 \\
$6 \mathrm{~m}$ & 0.000 & 0.000 & 0.001 & 0.007 & 0.026 & 0.068 \\
$1 \mathrm{y}$ & 0.000 & 0.002 & 0.009 & 0.026 & 0.057 & 0.104 \\
$2 \mathrm{y}$ & 0.008 & 0.018 & 0.038 & 0.070 & 0.112 & 0.165 \\
$3 \mathrm{y}$ & 0.024 & 0.045 & 0.075 & 0.115 & 0.164 & 0.220 \\
$4 \mathrm{y}$ & 0.047 & 0.077 & 0.115 & 0.161 & 0.215 & 0.273 \\
$5 \mathrm{y}$ & 0.076 & 0.112 & 0.157 & 0.208 & 0.265 & 0.327 \\
$10 \mathrm{y}$ & 0.260 & 0.322 & 0.388 & 0.457 & 0.529 & 0.602 \\
\hline
\end{tabular}

Notes: The table displays the unit costs $V\left(S_{0}, T\right)$ of implementing a one-sided target zone for a lifetime $T$ of 1 month (1m), 2 months ( $2 \mathrm{~m}), 3$ months ( $3 \mathrm{~m}), 6$ months $(6 \mathrm{~m}), 1$ year (1y), 2 years (2y), 3 years (3y), 4 years (4y), 5 years (5y) or 10 years (10y) and different floor levels $b$. The domestic and foreign risk-free interest rates equal $r=1 \%$ and $r^{f}=4 \%$. The spot and latent exchange rate at time $t=0$ (i. e., $S_{0}$ and $F_{0}$ ) both equal 1.25 with a volatility level of $\sigma=8 \%$.

Table 2: Unit costs of a one-sided target zone $\left(\mu^{\star}>0\right.$; Model 1$)$.

\begin{tabular}{lrrrrrr}
\hline $\boldsymbol{T}$ & \multicolumn{7}{c}{} & & $\boldsymbol{b}$ \\
\cline { 2 - 7 } & $\mathbf{1 . 0 0}$ & $\mathbf{1 . 0 5}$ & $\mathbf{1 . 1 0}$ & $\mathbf{1 . 1 5}$ & $\mathbf{1 . 2 0}$ & $\mathbf{1 . 2 5}$ \\
\hline $1 \mathrm{~m}$ & 0.000 & 0.000 & 0.000 & 0.000 & 0.001 & 0.022 \\
$2 \mathrm{~m}$ & 0.000 & 0.000 & 0.000 & 0.000 & 0.003 & 0.030 \\
$3 \mathrm{~m}$ & 0.000 & 0.000 & 0.000 & 0.000 & 0.006 & 0.036 \\
$6 \mathrm{~m}$ & 0.000 & 0.000 & 0.000 & 0.003 & 0.014 & 0.048 \\
$1 \mathrm{y}$ & 0.000 & 0.000 & 0.002 & 0.008 & 0.026 & 0.064 \\
$2 \mathrm{y}$ & 0.001 & 0.002 & 0.007 & 0.018 & 0.041 & 0.082 \\
$3 \mathrm{y}$ & 0.002 & 0.005 & 0.012 & 0.025 & 0.051 & 0.093 \\
$4 \mathrm{y}$ & 0.003 & 0.007 & 0.015 & 0.031 & 0.058 & 0.101 \\
$5 \mathrm{y}$ & 0.004 & 0.009 & 0.018 & 0.035 & 0.063 & 0.107 \\
$10 \mathrm{y}$ & 0.008 & 0.016 & 0.028 & 0.047 & 0.077 & 0.122 \\
\hline
\end{tabular}

Notes: The table displays the unit costs $V\left(S_{O}, T\right)$ of implementing a one-sided target zone for a lifetime T of 1 month (1m), 2 months ( $2 \mathrm{~m}), 3$ months $(3 \mathrm{~m}), 6$ months $(6 \mathrm{~m}), 1$ year $(1 \mathrm{y}), 2$ years (2y), 3 years (3y), 4 years (4y), 5 years (5y) or 10 years (10y) and different floor levels $b$. The domestic and foreign risk-free interest rates equal $r=4 \%$ and $r^{f}=1 \%$. The spot and latent exchange rate at time $t=0$ (i. e., $S_{0}$ and $F_{0}$ ) both equal 1.25 with a volatility level of $\sigma=8 \%$. 


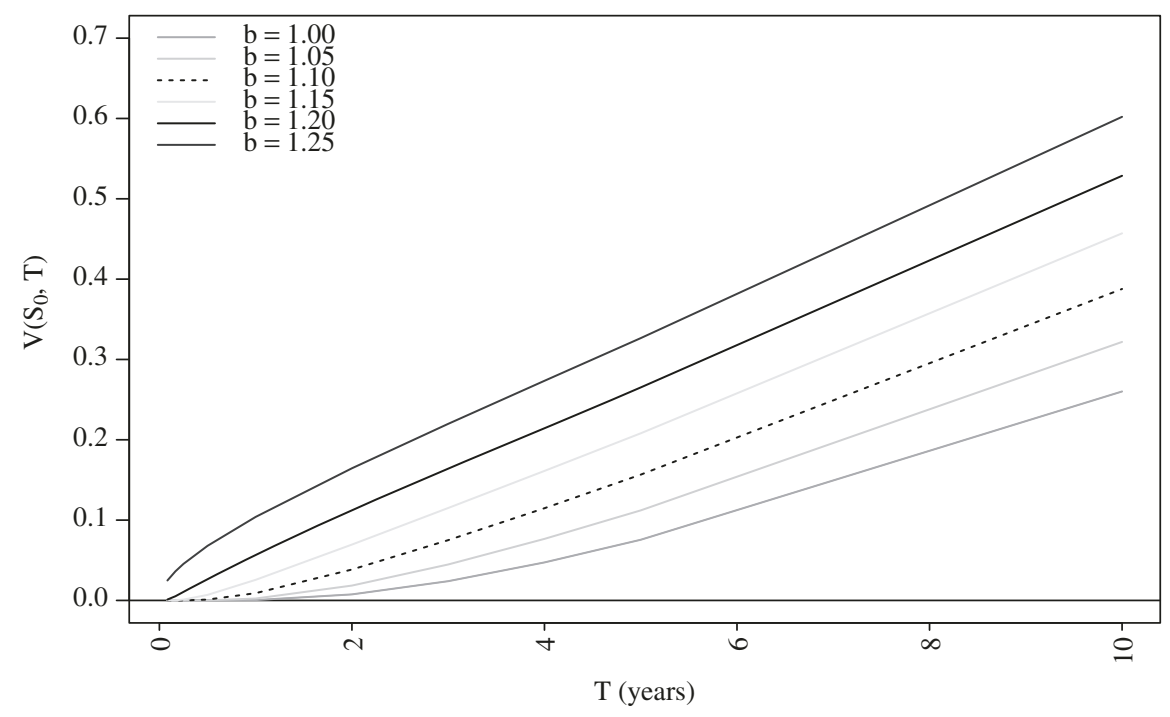

Figure 1: Unit costs of a one-sided target zone $\left(\mu^{\star}<0\right.$; Model 1).

Notes: The figure shows the unit costs $V\left(S_{0}, T\right)$ of implementing a one-sided target zone for a lifetime $T$ of 1 month (1m), 2 months ( $2 \mathrm{~m}), 3$ months ( $3 \mathrm{~m}), 6$ months (6m), 1 year (1y), 2 years (2y), 3 years (3y), 4 years (4y), 5 years (5y) or 10 years (10y) and different floor levels b. The domestic and foreign risk-free interest rates equal $r=1 \%$ and $r^{f}=4 \%$. The spot and latent exchange rate at time $t=0$ (i. e., $S_{0}$ and $F_{0}$ ) both equal 1.25 with a volatility level of $\sigma=8 \%$.

(whereby $\mu^{\star}$ would increase and become either positive or less negative) to lower the costs $V\left(S_{0}, T\right)$.

Before concluding this section, notice that when a central bank is considering whether to implement a one-sided target zone or not, the maximum costs of this exchange rate policy can be estimated ex-ante by setting $S_{0}=b$ and $F_{0}=F_{-1}$ in Equation (8), assuming that the spot exchange rate is close to the announced floor level just after announcing a minimum exchange rate policy and that the domestic currency is either fairly priced or overvalued prior to the announcement of the floor. ${ }^{9}$

9 It can be easily shown that $V\left(S_{0}, T\right)$ is decreasing in $S_{0}$ and $F_{0}$ (see Appendix D). Hence, since $S_{0} \geq b, S_{t} \geq F_{t}$ and assuming that the domestic currency was previously either fairly priced or overvalued (hence, the following condition holds: $F_{0} \geq F_{-1}$ ), it must be the case that these costs are at its maximum when $F_{0}=F_{-1}<b=S_{0}$. 


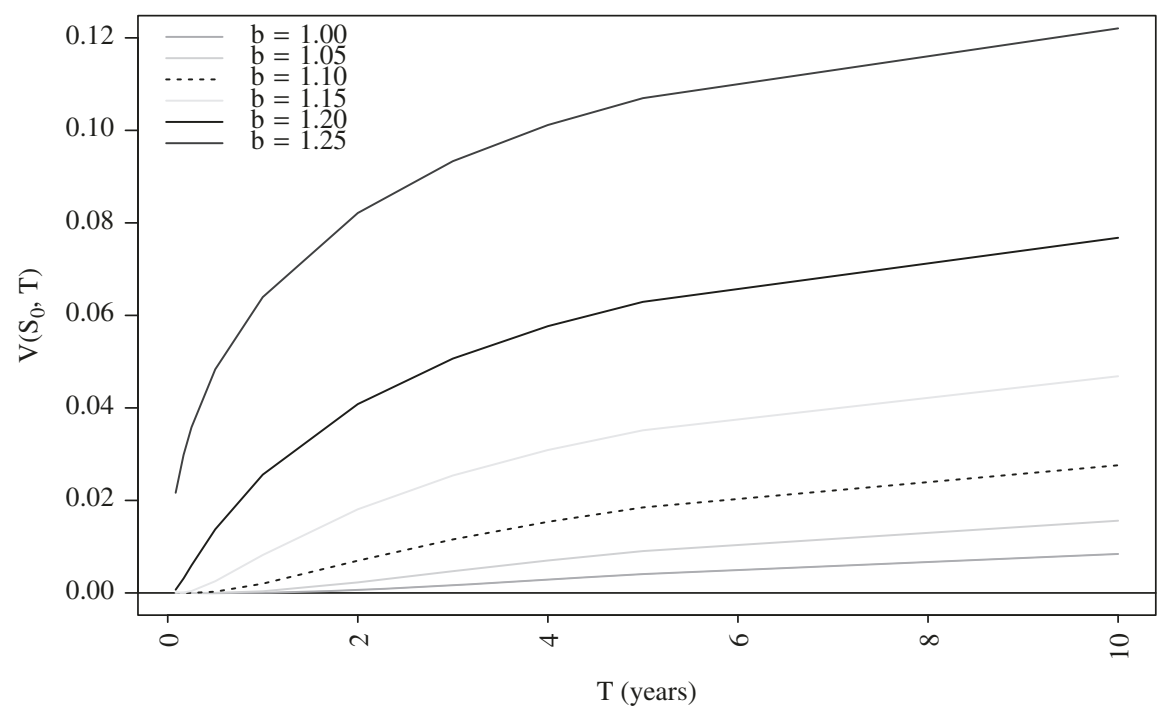

Figure 2: Unit costs of a one-sided target zone $\left(\mu^{\star}>0\right.$; Model 1).

Notes: The figure shows the unit costs $V\left(S_{0}, T\right)$ of implementing a one-sided target zone for a lifetime $T$ of 1 month (1m), 2 months ( $2 \mathrm{~m}), 3$ months ( $3 \mathrm{~m}), 6$ months $(6 \mathrm{~m}), 1$ year (1y), 2 years (2y), 3 years (3y), 4 years (4y), 5 years (5y) or 10 years (10y) and different floor levels $b$. The domestic and foreign risk-free interest rates equal $r=4 \%$ and $r^{f}=1 \%$. The spot and latent exchange rate at time $t=0$ (i. e., $S_{0}$ and $F_{0}$ ) both equal 1.25 with a volatility level of $\sigma=8 \%$.

\section{Robustness check: the costs under an alternative modeling approach}

Of course, there is room for using alternative models: The observed spot exchange rate $\left(S_{\mathrm{t}}\right.$ in Sections 2 and 3) can as well be modeled as the sum of the latent exchange rate ( $F_{t}$ in Sections 2 and 3 ) and the price of an American put option on the latent exchange rate $P^{A}\left(F_{t}, T\right)$ with an uncertain, but constant lifetime $T$, whereby the domestic central bank implicitly writes (cancels) put options, when it sells (buys) the foreign currency (Hanke, Poulsen, and WEISSENSTEINER 2015):

$$
S_{t}=F_{t}+P^{A}\left(F_{t}, T\right) .
$$

Since there are no closed-form formulas for non-perpetual American options when it is assumed that the underlying follows a geometric Brownian motion, Hanke, Poulsen, and Weissensteiner (2015) argue that the American put option will never be exercised before maturity, given the fact that both the interest rates in 
the domestic country they analyze (Switzerland) are close to zero and given that the interest rates in the foreign country (the euro zone) are larger. Consequently, the American put option on the latent exchange rate in Hanke, Poulsen, and WeISSENSTEINER (2015) can be replaced by a European put option $P\left(F_{t}, T\right):^{10}$

$$
S_{t}=F_{t}+P\left(F_{t}, T\right) .
$$

Moreover, from the point of view of the domestic central bank, the uncertain lifetime $T$ in their model can be replaced by a known maturity date $T$. The European put option in Hanke, Poulsen, and Weissensteiner (2015) can then be priced using the Garman and KoHLHAGEN (1983) model.

Under this modeling approach, EUR-CHF option contracts on the spot exchange rate $S_{t}$ can be interpreted as compound options in the period of interest. Hence, the costs associated with the monetary policy regime described in Hanke, Poulsen, and Weissensteiner (2015) can easily be estimated by applying their approach to estimate $F_{t}$ using EUR-CHF option prices and plugging the estimated values into the European put option price formula. Notice that the costs under this framework constitute the minimum costs of implementing a minimum exchange rate regime, as the price of the put option in Equation (12) (for $T \rightarrow 0$ ) is half as large as the costs implied by the modeling approach proposed in Sections 2 and 3 (see GERBER and PAfumi (2000) for a proof).

Nevertheless, since the approach in Hanke, Poulsen, and Weissensteiner (2015) results in option prices on the EUR-CHF FX rate that violate the put-call parity for compound options and therefore are not arbitrage-free, since Equation (12) does not hold in general ${ }^{11}$ and since the model in Section 3 is based on FX spot market data, this paper prefers an alternative estimation procedure due to HANKE, Poulsen, and Weissensteiner (2014) that relies on spot currency data instead. Their approach is based on the structural credit risk model on page $42 \mathrm{ff}$. in LANDo (2004). Moreover, the dynamics of the estimated latent EUR-CHF FX rate in Hanke, Poulsen, and Weissensteiner (2014) are closer to the results in Jermann (2015)

10 However, as the domestic central bank has the power to cancel the European put option at every point of time, from an investor's point of view, they should model the European put option as an Israeli option in the spirit of KIFER (2000) and KüHN and KYPRIANOU (2007), an option which puts an upper bound on the time value conceded to the option buyer by introducing the callable feature (Kunn and Kyprianou, 2007). Modeling the put option as an Israeli option would then make the put option less valuable.

11 As already mentioned, the approach in Hanke, Poulsen, and Weissensteiner (2014) and Hanke, Poulsen, and Weissensteiner (2015) both require ex-ante with $100 \%$ certainty that the domestic interest rate remains close to zero and that the foreign interest rate remains larger than the domestic interest rate throughout the period of interest and is therefore less general then the presented model (and not applicable to the Czech case, for instance). 
than the results in Hanke, Poulsen, and Weissensteiner (2015), which makes us feel more comfortable with the approach in Hanke, Poulsen, and Weissensteiner (2014).

Hanke, Poulsen, and Weissensteiner (2014) use the transition probability density of the stochastic process $\left\{\ln \left(F_{t}\right)\right\}$ which is assumed to follow a GBM and condition this density on the exchange rate just before the minimum exchange rate was announced (i. e., $\ln \left(F_{-1}\right)$ ). Using the definition of the observed spot exchange rate in Equation (12) and the Garman-Kohlhagen put option price formula, applying both the transformation and the inverse function theorem, taking the natural logarithm and maximizing the resulting log-likelihood, they obtain the time series of the latent exchange rate $F_{t}$ in the period of interest by "inverting" the put option price formula numerically. The costs of implementing a one-sided target zone can then be estimated by plugging in the parameter estimates into Equation (12). The results of this approach will be denoted by "model 2".

Alternatively, the costs of enforcing a minimum exchange rate regime can be proxied by the modeling approach in IMAI and BoyLE (2001), adjusting Equation (14) in their paper for the case of currencies. Their model is based on a lookback option on the latent exchange rate $F_{t}$ and is closely related to the model in Section 3. Hence, using the estimated latent exchange rate $\hat{F}_{t}$ in HANKE, Poulsen, and Weissensteiner (2014), setting $b=1.20$ and $T=1 \mathrm{~m}, 6 \mathrm{~m}$ and $1 \mathrm{y}$, respectively, the costs approximately equal: ${ }^{12}$

$$
\begin{aligned}
V\left(F_{t}, \tilde{T}\right)= & b \exp ^{\left(r^{f}-r\right) \tilde{T}}\left(1-\frac{1}{\theta}\right) \Phi\left(\frac{\ln \left(b_{t}^{\prime} / F_{t}\right)-\left[\mu^{\star}-\sigma^{2} / 2\right] \tilde{T}}{\sigma \sqrt{\tilde{T}}}\right) \\
& +\frac{b}{\theta}\left(\frac{b_{t}^{\prime}}{F_{t}}\right)^{\theta} \Phi\left(\frac{\ln \left(b_{t}^{\prime} / F_{t}\right)+\left[\mu^{\star}+\sigma^{2} / 2\right] \tilde{T}}{\sigma \sqrt{\tilde{T}}}\right) \\
& +F_{t}\left\{M_{t} \Phi\left(\frac{\ln \left(F_{t} / b_{t}^{\prime}\right)+\left[\mu^{\star}+\sigma^{2} / 2\right] \tilde{T}}{\sigma \sqrt{\tilde{T}}}\right)-1\right\}
\end{aligned}
$$

with $M_{t}=\max \left\{1, b / \max _{0 \leq s \leq t} F_{s}\right\}, b_{t}^{\prime}=b / M_{t}$ and $\tilde{T} \equiv T-t$. This model is called "model 3 " in the following.

\section{Empirical results}

In this section, the costs of implementing a one-sided target zone are estimated for the case of Switzerland from September 6, 2011 to January 14, 2015. The

12 Since both the transition probability density and $F_{0}$ are given, alternatively, the expectation maximization algorithm can be applied to obtain the expected value of $F_{t}$. 
present study focuses on the Swiss case, since for the Czech case the lower boundary is not fixed to EUR-CZK 27, but only to be close to that floor level and because there the step of proxying the American put option by a European put option (arguing that the foreign interest rates are consistently larger than the domestic interest rates and that the latter are close to zero; see footnote 11 in Section 4 for more details) is less convenient, since for this currency pair the drift rate $\mu^{\star}$ has changed the sign several times since November $7,2013,{ }^{13}$ which is another argument why the approach in Section 3 is preferred to the alternative models in Section 4.

\subsection{Data}

To calculate the costs of implementing a one-sided target zone in Equations (10), (12) and (13), the domestic and foreign risk-free interest rates $r$ and $r^{f}$ are proxied by the corresponding CHF LIBOR and EUR LIBOR interest rates for contract maturities of 1 month (1m), 6 months $(6 \mathrm{~m})$ and 12 months (1y). For specifying the volatility level $\sigma$, option implied volatilities for call and put options on the EUR-CHF spot FX rate from Bloomberg with an option delta of $\Delta \pm 25 \%$ and contract maturities of $1 \mathrm{~m}, 6 \mathrm{~m}$ and $1 \mathrm{y}$ are used, covering the period from September 6, 2011 to January 14, 2015. Specifically, it is assumed that the domestic central bank uses the previous day's implied volatility as an estimate for today's implied volatility, following WhaLEy (1993) and BAKSHI, CAO, and Chen (1997), among others, as compared to alternative measures, this procedure has good forecasting power (see, e.g., SATchell (2007) and WANG and DAIGLER (2011)). The volatility smile effect is captured by applying the Vanna-Volga approximation as discussed in Castagna and Mercurio (2005), thereby getting implied volatilities that are consistent with the previous day's smile curve. ${ }^{14}$ The minimum exchange rate $b$ equals EUR-CHF 1.20. The exchange rate after announcing the implementation of a strong-side commitment $S_{O}$ is set equal to the recorded EUR-CHF exchange rate on September 6, 2011, which is (approximately) equal to EUR-CHF 1.21. The lifetime of the one-sided target zone $T$ is set equal to the aforementioned FX option contract maturities.

13 Measured by the corresponding CZK PRIBOR and EUR LIBOR interest rates.

14 More details about the Vanna-Volga method can be found in, e. g., Castagna and Mercurio (2005), Castagna and Mercurio (2007), Wystup (2010b) and Bossens et al. (2010). 


\subsection{The costs of implementing a one-sided exchange rate target zone}

In this section and to exemplify the theoretical model 1, the unit costs of the SNB's exchange rate policy vis-à-vis the euro currency from September 6, 2011 to January 14, 2015 are analyzed. During this period, the SNB intervened with unsterilized FX interventions (i.e., by increasing just sufficiently the money supply to maintain the EUR-CHF FX rate above the minimum exchange rate), whenever the spot EUR-CHF FX rate touched the EUR-CHF 1.20 floor.

Figure 3 shows the estimated target zone costs for several maturities, ranging from 1 month to up to 1 year, assuming that the EUR-CHF exchange rate follows a RGBM after September 6, 2011. The figure indicates that initially, i. e., in the weeks and months after announcing the minimum exchange rate of EURCHF 1.20, the costs of maintaining the floor were relatively large. Moreover, Figure 3 is also in line with the intuition that the larger the lifetime $T$ of the onesided target zone (compare, for instance, $V_{1 m}$ with $V_{1 y}$ ), the larger are the costs of enforcing a minimum exchange rate regime, since it becomes more likely that the domestic central bank will have to intervene in the future. ${ }^{15}$

Interestingly, Mario Draghi's “Whatever it takes”-statement on July 26, 2012 had a minor effect on the target zone costs. It was not until the ECB launched the Outright Monetary Transaction (OMT) program on September 6, 2012 that the costs decreased significantly. This date initiated a period where the latent EUR-CHF FX rate $F_{t}$ continually increased and the costs of maintaining a target zone continually fell, until these costs reached a global minimum level for $V_{1 y}$ in summer 2014. ${ }^{16}$ This low cost level may explain why the SNB continued implementing the minimum exchange rate regime until the SNB finally decided to abandon the target zone regime on January 15, 2015. Figure 3 also indicates that presumably in spring 2013, when both the difference between the spot and latent EUR-CHF FX rate had reached an all-time low on May 22, 2013, ${ }^{17}$ whereby the Swiss currency had reached an all-time low since the introduction of the EUR-CHF 1.20 floor vis-àvis the euro and was close to being priced as in a free-floating exchange rate regime, and when the costs of maintaining a one-sided target zone were relatively high (in the period from March 2013 until the end of August 2014, the highest cost

15 Given the prominent role of the CHF as a safe haven currency in periods of global financial instability, this argumentation seems especially plausible in the period of interest.

$16 V_{6 m}$ and $V_{1 y}$ reached their global minima on November 27, 2013 and July 31, 2014, respectively.

17 Moreover, on this day, both the spot and latent EUR-CHF FX rate had reached an all-time high. 


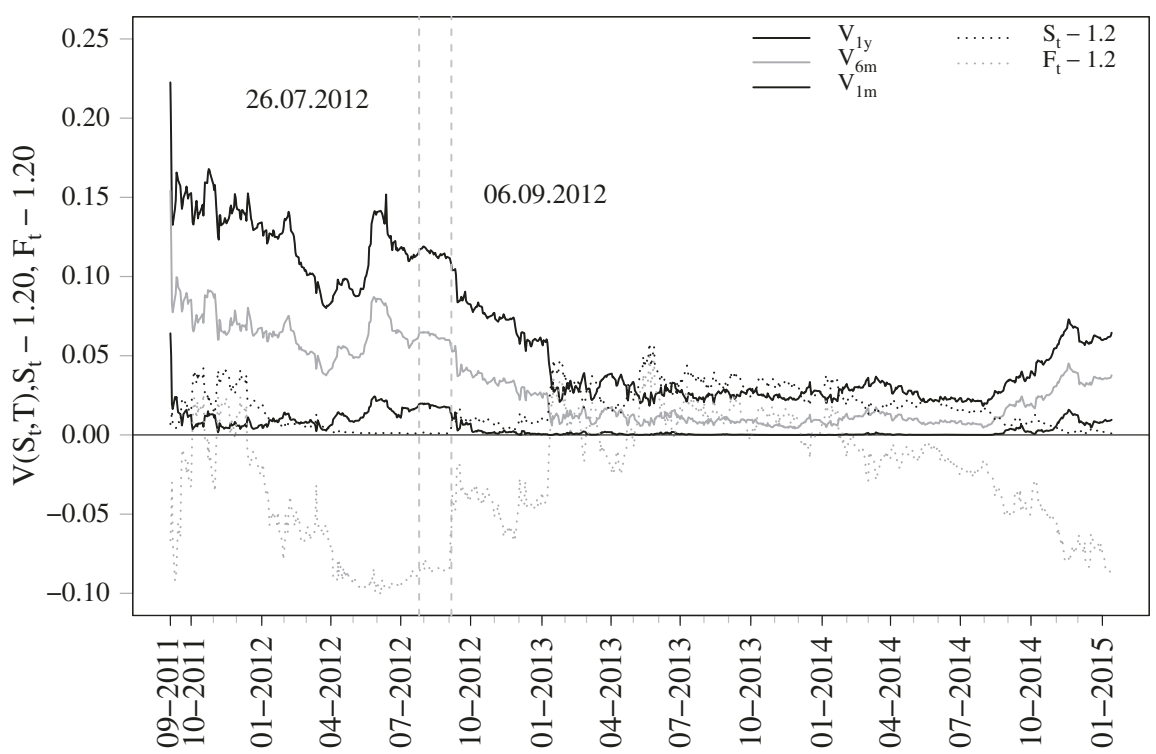

Figure 3: Target zone costs under RGBM (Model 1).

Notes: The figure shows the costs (in CHF) of implementing a one-sided target zone for a lifetime of 1 month $\left(V_{1 m}\right), 3$ months $\left(V_{3 m}\right)$ or 1 year $\left(V_{1 y}\right)$, respectively, under the assumption that the EURCHF exchange rate follows a reflected geometric Brownian motion (RGBM) from September 6, 2011 to January 14, 2015. The first marked date (26.07.2012) refers to the announcement of the "Draghi put" ("Whatever it takes"), the second marked date (06.09.2012) to the date when the European Central Bank launched the Outright Monetary Transaction (OMT) program. The dotted lines display the deviation of the spot and the latent FX rate $S_{t}$ (in black) and $F_{t}$ (in grey) from the EUR-CHF 1.20 floor, respectively. Data source: Bloomberg. CHF exchange rate float freely again, as removing the lower boundary may not have caused the EUR-CHF exchange rate to fall as extremely as it happened on January 15, 2015 and as the costs of further enforcing the minimum exchange rate policy for a further year $\left(V_{1 y}\right)$ were high.

levels for $V_{6 m}$ and $V_{1 y}$ were reached on April 3, 2013), it would have been a good period to let the EUR-CHF exchange rate oat freely again, as removing the lower boundary may not have caused the EUR-CHF exchange rate to fall as extremely as it happened on January 15, 2015 and as the costs of further enforcing the minimum exchange rate policy for a further year $\left(V_{1 y}\right)$ were high.

Comparing the situation in spring 2013 to the period when the SNB decided to abandon the EUR-CHF 1.20 floor on January 15, 2015, some key macroeconomic variables (e. g., both the Swiss GDP growth rate and the conditional inflation forecast in spring 2013 vs. 4Q-2014 and the real effective FX rate vis-à-vis Switzerland's major trading partners in Figure E.1 in Appendix E) reveal that abandoning the EUR-CHF 1.20 floor in spring 2013 instead of January 2015 might 
have been less harmful, since the GDP growth rates in Switzerland and France or Germany were higher in spring 2013 than in 4Q-2014 (see the webpage of the SNB), the conditional inflation forecasts in both periods were numerically of similar size (see the webpage of the SNB) and the real effective FX rate had reached an all-time low in spring 2013 since the euro zone crisis erupted in 2010/2011.

Moreover, a glance at Figure 3 indicates that both especially the short-term costs ( $V_{1 m}$ and $\left.V_{6 m}\right)$ and the gap between the spot and latent EUR-CHF FX rate were considerably larger in the latter period. Consequently, without the abandonment of the floor, the SNB presumably might have had to intervene in the currency market to enforce the EUR-CHF 1.20 floor (as it was already the case in 2012) in winter and spring 2015. The results in Figure 3 also show that the SNB could have anticipated the EUR-CHF FX rate volatility that was observed after abandoning the floor, since the difference between $S_{t}$ and $F_{t}$ was rather large in January 2015. Alternatively, instead of completely abandoning the EUR-CHF 1.20 floor, the SNB could have lowered the floor to a lower level, in the spirit of Hertrich and Zimmermann (2015), an alternative also supported by BERNHOLz (2015). All in all, however, it seems that the timing of the SNB in deciding to discontinue the floor was rather good.

Interestingly, the dynamics of the target zone costs qualitatively accords with the results in LóPEZ and MENDIZÁBAL (2003), who develop a target zone model and compare the costs of implementing a target zone in terms of both the interest rate variability and the exchange rate variability to alternative regimes, whereby the more credible a target zone is, the smaller the costs of a target zone are, since Figure 2 in HerTRICH and Zimmermann (2015) indicates that the credibility of the SNB's minimum exchange rate policy was relatively large in the period where the target zone costs were rather low (in the period from March 2013 until the end of August 2014 in Figure 3). Similarly and in general, a (potential) lack of or imperfect credibility of a target zone regime makes the enforcement of a floor more expensive, since the domestic central bank has to buy relatively larger amounts of the foreign currency. If these interventions are unsterilized, the domestic interest rate will fall accordingly, increasing the target zone costs in, for instance, the framework of LóPEz and MENDIZÁBAL (2003). Estimating the (relative) weights that the SNB's policymakers attached to the variability of the exchange rate vs. the variability of the interest rates in the period of interest using a standard policy loss function may reveal why the SNB finally decided to abandon the EUR-CHF 1.20 floor on January 15, 2015.

The result in Figure 3 can also be related to the SNB's exchange market interventions since September 6, 2011. Scaling $V\left(S_{t}, \tilde{T}\right)$ in Equation (10) by $S_{t}$, the implied (percentage) misalignment can also be related to the SNB's unsterilized interventions in March 2009 (or August 2011), when the SNB intervened in the FX market with unsterilized interventions (see Humpage (2013) for more 
details). As the empirical evidence in August 2011 may be more exceptional than the former episode, which motivated the SNB to announce a minimum exchange rate regime, this paper uses the data from the former episode in the following: According to the SNB's statistical database, the SNB's EUR-denominated FX reserves increased by EUR 4.538bn in 1Q-2009. As documented in HumPage (2013), the SNB started to intervene in the EUR-CHF spot market in March 2009 and most likely intervened in the period from March 12 to March 16. In total, the Swiss franc depreciated vis-à-vis the euro currency by approximately $2 \%$ from March 12 to March 31. Therefore, focusing on the required depreciation for a lifetime of a minimum exchange rate regime of one year as of September 7, 2011, September 7, 2012, September 7, 2013 and the same monthly metric from September 7, 2014 onwards, the SNB would have had to buy EUR 62.33bn ${ }^{18}$ in the period of interest, compared to an actual increase in the size of the SNB's EUR reserves of EUR 84.61bn. ${ }^{19}$ At this stage it is worth mentioning that estimating the volume or size of FX interventions by analyzing the changes in the central banks' FX reserves is a standard approach in the strand of literature on central bank interventions (see, e.g., Levy-Yeyati, Sturzenegger, and Gluzmann (2013), Adler and Tovar (2014) or Daude, Levy-Yeyati, and Nagengast (2014)).

Combining the required depreciation from model 1 with the results documented in AdLer, LisAcK, and Mano (2015), whereby the purchase of foreign currency in the order of 1 percentage point of GDP causes a depreciation of the nominal exchange rate in the range of [1.7-2.0] percent, it implies that the SNB would have had to purchase EUR currency in the range of [7.70-9.06] percent of the Swiss GDP in year 1 (or CHF [48.7bn-57.3bn]), ${ }^{20,21}$ [4.30-5.06] percent in year 2 (or CHF [27.2bn-32.0bn]) in year 2, [1.03-1.21] percent in year 3 (or CHF [6.5bn-7.6bn]) and [0.71-0.84] percent in the last quarter (or CHF [4.5bn-5.3bn]), respectively.

To summarize the previous paragraphs: The presented empirical analysis reveals important insights about the costs (in terms of the extra amount of foreign currency) of implementing and maintaining a minimum exchange rate regime and the factors that have an impact on these costs. Furthermore, the results show how financial market information can be used by central banks to

$18(15.40 \%+8.60 \%+2.05 \%+0.82 \%+0.60 \%) / 2.00 \%$ * EUR 4.538bn $\approx$ EUR 62.33bn, where the numbers in parentheses equal the required depreciation in the indicated periods.

19 This number equals $1 / 3$ the change in the SNB's EUR reserves in 3Q-2011, the change in the EUR reserves between 3Q-2011 and 4Q-2014 and 1/6 the change in the EUR reserves in 1Q-2015. $2015.4 \% / 2 \%$ * Swiss GDP and 15.4\%/1.7\% * Swiss GDP, respectively.

21 Averaging the quarterly Swiss GDP from 4Q-2011 to 4Q-2014 and multiplying this number by four, the annual Swiss GDP amounts to approximately CHF 633.06bn in the period of interest. 
assess the costs associated with the implementation of unilateral exchange rate policies. Before concluding this section, it is nevertheless worth emphasizing that the size of the SNB's FX interventions in the period of interest is extraordinarily large: According to FrATzSCHER et al. (2015) (and ignoring the fact that the available information on central bank FX interventions only covers sterilized interventions, which is a reasonable approximation in a near-zero interest rate environment, given the evidence from Japan in the 1990s, where the distinction between both intervention approaches became obsolete (SPIEGEL, 2003)), ${ }^{22}$ the average daily net transaction volume is equal to approximately USD $122.1 \mathrm{~m}$ for the larger advanced economies ${ }^{23}$ and actual activity is reported by central banks on $43.5 \%$ of the trading days in turbulent times within narrow band regimes. Hence, using these numbers and multiplying these numbers with the average USD-CHF FX rate of 0.9258 in the period of interest, the size of interventions would amount to approximately CHF $42.6 \mathrm{bn} .^{24}$

Which arguments may explain this observation? Since the Krugman model relies on a simple flexible-price monetary model (Froot and OBSTFELd, 1991), it may be hypothesized that some of the underlying assumption may be violated in the period of interest. For instance, it may be argued that the assumption of a stable domestic money demand function or the validity of the purchasing power parity is questionable in periods of financial turmoil. As a consequence, the efficiency of unsterilized FX interventions may be lower than in tranquil periods. Other explanations may be that the Swiss target zone vis-à-vis the euro currency was not perfectly credible (HerTrich and Zimmermann (2015) and JERmann (2015)). Indeed, Fratzscher et al. (2015) document that FX interventions are more effective, if these transactions are executed in line with prior FX rate trends, which may partially explain the extraordinary size of the SNB's euro purchases in the period of interest. Alternatively, assuming that the Swiss currency was indeed fairly priced and not overvalued prior to the announcement of the floor, the difference between the average EUR-CHF FX rate in the period of interest of 1.22 minus the average EUR-CHF FX rate in the month prior to the introduction of the floor (i. e., from August 08, 2011 to September 5, 2011) of 1.13 implies a depreciation of $8.13 \%$. Combining this number with the results documented in ADLER, LISACK, and MANo (2015), whereby the purchase of foreign currency in the order of

22 Alternatively, the target zone costs can be interpreted as the maximum intervention size, since sterilized interventions are less efficient than unsterilized interventions and therefore require a larger size of FX interventions to achieve the same targeted exchange rate change.

23 Given the relevance of the Swiss currency in FX markets according to the most recent BIS statistics (BIS, 2014), Switzerland can be considered a "large" economy.

24 USD-CHF 0.9258 * USD $122.1 \mathrm{~m} * 43.5 \%$ * 260 * $10 / 3 \approx$ CHF 42.6bn. 
1 percentage point of GDP causes a depreciation of the nominal exchange rate in the range of [1.7-2.0] percent, it implies that the SNB would have had to purchase EUR currency in the range of [4.07-4.79] percent of the Swiss GDP, which is much larger than the average size of interventions in terms of GDP in the range of [0.02-0.05] percent documented in FrATzSCHER et al. (2015). Hence, a total transaction volume in the range of CHF 25.7bn-CHF 30.3bn might have caused a depreciation of around $8.13 \%$ in the period of interest. Comparing this estimated size of FX interventions with the actual EUR purchases and having in mind the EUR-CHF FX rate dynamics since January 15, 2015, this may indicate that the EUR-CHF 1.20 floor presumably pushed the value of the euro currency vis-à-vis the Swiss franc beyond its fundamental value, thereby creating a "Peso"-problem.

\subsection{Robustness check}

A closer look at Figures E.2 and E.3 in Appendix E, where the target zone costs according to models 2 and 3 (see Section 4) are plotted, confirms the conjectures in the previous paragraphs, since the evolution of the target zone costs over time accords with the dynamics of the data in Figure 3. Hence, model 1 seems to deliver results that are qualitatively similar to the results of alternative modeling approaches. Consequently, the underlying assumptions of the model seem to play a minor role.

\section{Conclusion}

In the aftermath of the recent financial crisis, the central banks of small open economies such as the Czech National Bank and the Swiss National Bank introduced a lower boundary vis-à-vis the euro currency, the currency of their most important trading partners (i. e., the countries from the euro zone). This policy has generated a strand of literature that analyzes these episodes. The present paper contributes to this target zone literature by proposing a model that allows central banks and policymakers to quantify the expected costs of implementing a strong-side commitment for an exchange rate that is (potentially) "overvalued" prior to the announcement of the exchange rate floor. The paper proceeds and analyzes the impact that the parameters that are under the control of the domestic central bank have on these target zone costs, namely the lifetime of the target zone, the domestic risk-free interest rate and the implemented floor level. The presented model suggests first, that these costs are larger when the 
drift rate of the exchange rate is negative, as this implies that the foreign currency is expected to depreciate vis-à-vis the domestic currency over time according to interest parity. Second, a shorter lifetime of the target zone in general implies lower target zone costs. Third, the lower the implemented floor level, the more costly it is for the domestic central bank to maintain a one-sided target zone.

An empirical application to the recently discontinued minimum exchange rate regime that the Swiss National Bank implemented from September 6, 2011 to January 15, 2015 complements the paper and adds insights into the presented model, emphasizing the relevance of applying models that allow central banks both to estimate these costs before announcing a unilateral one-sided target zone and to monitor these costs during the period where it is enforced. The model also offers central banks and policymakers a tool for identifying ex-ante a suitable date to discontinue the exchange rate target zone regime.

The empirical evidence suggests first, that there may have been better dates to abandon the EUR-CHF target zone from an ex-post perspective (although the specific date when the SNB decided to discontinue the floor was well chosen, given the circumstances) and second, that the actual size of these costs might have otherwise been substantial. The robustness of the presented model is assessed by applying two alternative approaches, which yield qualitatively comparable results. The presented model therefore allows central banks and policymakers to infer relevant foreign exchange rate information (from spot and/ or from option markets), especially when considering ex-ante the announcement of an exchange rate floor or when monitoring the costs of maintaining a target zone while it is implemented.

Given the evidence that in the 1990s the Deutsche Bundesbank not only intervened at the officially declared exchange rate boundaries while the Exchange Rate Mechanism (ERM) of the European Monetary System (EMS) was in place (FLOOD and GARBER, 1989), analyzing whether the SNB's actual interventions took place at a level above the EUR-CHF 1.20 floor, in the spirit of the results documented in Bartolini and Prati (1999) or Veestraeten (2007) for the ERM regime, would be a natural next step of the presented analysis.

\section{References}

Adler, G., N. LisACK and R. C. Mano (2015): Unveiling the Effects of Foreign Exchange Intervention: A Panel Approach. Working Paper 15/130, IMF.

Adler, G. and C. E. Tovar (2014): Foreign Exchange Interventions and their Impact on Exchange Rate Levels. Monetaria January-June, 1-48. 
BIS (2014): Global Foreign Exchange Market Turnover in 2013. Triennial Central Bank Survey, Bank for International Settlement.

BAKSHI, G., C. CAO and Z. Chen (1997): Empirical Performance of Alternative Option Pricing Models, Journal of Finance 52(5), 2003-2049.

BALtenSPERger, E. (2015): SNB-Doyen will neue Untergrenze. In: Interview with Neue Zürcher Zeitung (January 11, 2015).

Bartolini, L. and A. Prati (1999): Soft Exchange Rate Bands and Speculative Attacks: Theory, and Evidence From the ERM Since August 1993, Journal of International Economics 49, 1-29.

Bergman, Y. Z. (1996): Equilibrium Asset Price Ranges, International Review of Financial Analysis 5(3), 161-169.

Bernholz, P. (2015): The Swiss Experiment: From the Lower Bound to Flexible Exchange Rates, Cato Journal 35(2), 403-410.

Bertola, G. and L. E. O. Svensson (1993): Stochastic Devaluation Risk and the Empirical Fit of Target-Zone Models, Review of Economic Studies 60(3), 689-712.

Bossens, F., G. Rayée, N. Skantzos and G. Deelstra (2010): Vanna-Volga Methods Applied to FX Derivatives: From Theory to Market Practice, International Journal of Theoretical and Applied Finance 13(8), 1293-1324.

Castagna, A. and F. Mercurio (2005): Consistent Pricing of FX Options. Internal Report, Banca IMI.

Castagna, A. and F. Mercurio (2007): The Vanna-Volga Method for Implied Volatilities. Risk Magazine Autumn, 39-44.

Chaboud, A. and O. Humpage (2005): An Assessment of the Impact of Japanese Foreign Exchange Intervention: 1991-2004, International Finance Discussion Papers 824, 1-41.

Chen, Y. -F., M. Funke and N. Glanemann (2013): Off-the-Record Target Zones: Theory with an Application to Hong Kongs Currency Board, Studies in Nonlinear Dynamics and Econometrics 17(4), 373-393.

Chen, Z. and A. Giovannini (1992): Target Zones and the Distribution of Exchange Rates, Economics Letters 40, 83-89.

Cottareli, C. and P. Doyle (1999): Disinflation in Transition, 1993-97, International Monetary Fund Occasional Paper 179, 1-45.

Cox, D. and H. Miller (1965): The Theory of Stochastic Processes. Chapman and Hall, London.

Daude, C., E. Levy-Yeyati and A. Nagengast (2014): On the Effectiveness of Exchange Rate Interventions in Emerging Markets. Working Paper 324, OECD Development Center.

Dominguez, K. M. (1998): Central Bank Intervention and Exchange Rate Volatility, Journal of International Money and Finance 17(1), 161-190.

Flood, R. P. and P. M. Garber (1989): The Linkage Between Speculative Attack and Target Zone Models of Exchange Rates. Working Paper 89/30, IMF.

Flood, R. and N. Marion (1994): The Size and Timing of Devaluations in Capital-Controlled Developing Countries. Working Paper Series 4957, NBER.

Flood, R. P., A. K. Rose and D. J. Mathieson (1991): An Empirical Exploration of Exchange Rate Target-Zones, Carnegie-Rochester Conference Series on Public Policy 35, 7-66.

Fratzscher, M., O. Gloede, L. Menkhoff, L. Sarno and T. Stöhr (2015): When is Foreign Exchange Intervention Effective? Evidence from 33 Countries. Discussion Paper, Deutsches Institut für Wirtschaftsforschung.

Froot, K. A. and M. ObStFeld (1991): Exchange-Rate Dynamics Under Stochastic Regime Shifts: A Unified Approach, Journal of International Economics 31, 203-229. 
Garman, M. B. and S. W. KohlHagen (1983): Foreign Currency Option Values, Journal of International Money and Finance 2(3), 231-237.

Geman, H. (2015): Agricultural Finance: From Crops to Land, Water and Infrastructure. John Wiley \& Sons, Chichester.

Genberg, H. and C. -H. Hui (2011): The Credibility of Hong Kongs Link From the Prespective of Modern Financial Theory, Journal of Money, Credit and Banking 43(1), 185-206.

Gerber, H. and G. Pafumi (2000): Pricing Dynamic Investment Fund Protection, North American Actuarial Journal 4(2), 28-37; Discussion 37-41.

Glasserman, P. (2004): Monte Carlo Methods in Financial Engineering. Springer, Heidelberg.

Graversen, S. E. and A. N. Shiryaev (2000): An Extension of P. Lévy's Distributional Properties to the Case of a Brownian Motion with Drift, Bernoulli 6(4), 615-620.

Hanke, M., R. Poulsen and A. Weissensteiner (2014): Analyzing the Swiss National Bank's Euro Exchange Rate Policy: A Latent Likelihood Approach. Working Paper, available at SSRN 2515210.

Hanke, M., R. Poulsen and A. Weissensteiner (2015): Where Would the EUR/CHF Exchange Rate Be Without the SNB's Minimum Exchange Rate Policy? Journal of Futures Markets 35(12), 1103-1116.

HaRRISON, J. M. (1985): Brownian Motion and Stochastic Flow Systems, Reprint 1990 Edition. John Wiley \& Sons, New York.

Hertrich, M. (2016): The Distribution of Exchange Rates under a Minimum Exchange Rate Regime. forthcoming in the Journal of Applied Economics.

Hertrich, M. and H. Zimmermann (2015): On the Credibility of the Euro/Swiss Franc Floor: A Financial Market Perspective. Working Paper, available at SSRN 2290997.

Hul, C., C. Lo and T. Fong (2015): A Quasi-Bounded Model for Swiss Franc's One-Sided Target Zone During 2011-2015. Working Paper, Hong Kong Institute for Monetary Research.

Humpage, O. (2013): The Limitations of Foreign-Exchange Intervention: Lessons from Switzerland. Economic Commentary 2013-13, Federal Reserve Bank of Cleveland.

Humpage, O. and J. Ragnartz (2006): Swedish Intervention and the Krona Float, 1993-2002, Sveriges Riksbank Working Paper Series 192, 1-40.

ICC Research Foundation (2013): ICC Open Markets Index.

ImAI, J. and P. P. Boyle (2001): Dynamic Fund Protection, North American Actuarial Journal 5(3), 31-49; Disscussion 49-51.

INGERSOLL, J. E. JR (1987): Theory of Financial Decision Making. Rowman \& Littlefield, Totowa.

Jermann, U. J. (2015): Financial Markets' Views about the Euro-Swiss Franc Floor. Working Paper, available at SSRN 2490086.

KIFER, Y. (2000): Game Options, Finance and Stochastics 4(4), 443-463.

Ko, B., E. SHIU and L. Wel (2010): Pricing Maturity Guarantee with Dynamic Withdrawal Benefit, Insurance: Mathematics and Economics 47(2), 216-223.

KRUgman, P. R. (1991): Target Zones and Exchange Rate Dynamics, Quarterly Journal of Economics 106(3), 669-682.

Kugler, P. and B. Weder (2009): The Demise of the Swiss Interest Rate Puzzle. Working Paper, Faculty of Business and Economics - University of Basel.

KüHn, C. and A. Kyprianou (2007): Callable Puts as Composite Exotic Options, Mathematical Finance 17(4), 487-502.

LAnDo, D. (2004): Credit Risk Modeling. Princeton University Press, Princeton. 
Lera, S. C. and D. Sornette (2016): Quantitative Modelling of the EUR/CHF Exchange Rate During the Target Zone Regime of September 2011 to January 2015, Journal of International Money and Finance 63, 28-47.

Levy-Yeyati, E., F. Sturzenegger and P. A. Gluzmann (2013): Fear of Appreciation, Journal of Development Economics 101, 233-247.

Lo, C., C. Hul, T. Fong and S. Chu (2015): A Quasi-Bounded Target Zone Model - Theory and Application to Hong Kong Dollar, International Review of Economics and Finance 37(37), 1-17.

López, J. R. and H. R. Mendizábal (2003): On the Choice of an Exchange Regime: Target Zones Revisited. Working Paper.

MusIELA, M. and M. RutKowskI (2009): Martingale Methods in Financial Modelling. Springer, Heidelberg.

Neuman, E. and A. Schied (2015): Optimal Portfolio Liquidation in Target Zone Models and Catalytic Superprocesses. Working Paper.

ReISWICH, D. and U. Wystup (2010): A Guide to FX Options Quoting Conventions, Journal of Derivatives 18(2), 58-68.

SARno, L. and M. P. TAYLoR (2001): Official Intervention in the Foreign Exchange Market: Is It Effective and, if so, How Does It Work? Journal of Economic Literature 39(3), 839-868.

Satchel, S. (2007): Forecasting Expected Returns in the Financial Markets. Academic Press, London.

Sковокнод, А. V. (1961): Stochastic Equations for Diffusion Processes in a Bounded Region, Theory of Probability and Its Applications 6(3), 264-274.

SPIEGEL, M. (2003): Japanese Foreign Exchange Intervention. Pacific Basin Notes, Federal Reserve Bank of San Francisco Economic Letter.

Studer-Suter, R. and A. Janssen (2014): The Swiss Franc's Honeymoon. Working Paper, University of Zurich.

Svensson, L. E. O. (1991): The Simplest Test of Target Zone Credibility, International Monetary Fund Staff Papers 38(3), 655-665.

Svensson, L. E. O. (1992a): An Interpretation of Recent Research on Exchange Rate Target Zones, Journal of Economic Perspectives 6(4), 119-144.

Svensson, L. E. O. (1992b): The Foreign Exchange Risk Premium in a Target Zone Model with Devaluation Risk, Journal of International Economics 33(1), 21-40.

Veestraeten, D. (2000): Pricing of Currency Options in Credible Exchange Rate Target Zones: An Extension and an Alternative Valuation Approach. Discussions Paper Series 00.31, Catholic University of Leuven.

Veestraeten, D. (2007): The Presence of Target Zone Nonlinearities When Narrower Bands Exist Within Official Zones, Applied Economics 39, 449-452.

Veestraeten, D. (2008): Valuing Stock Options When Prices Are Subject to a Lower Boundary, Journal of Futures Markets 28(3), 231-247.

Veestraeten, D. (2013): Currency Option Pricing in a Credible Exchange Rate Target Zone, Applied Financial Economics 23(11), 951-962.

Wang, Z. and R. DaIGLER (2011): The Performance of VIX Option Pricing Models: Empirical Evidence Beyond Simulation, Journal of Futures Markets 31(3), 251-281.

WhaLeY, R. (1993): Derivatives on Market Volatility: Hedging Tools Long Overdue, Journal of Derivatives 1(1), 71-84.

Wystup, U. (2010a): Foreign Exchange Symmetries, in: R. Cont (ed.) Encyclopedia of Quantitative Finance, Vol. 2. John Wiley \& Sons, Chichester, 752-759.

Wrstup, U. (2010b): Vanna-Volga Pricing, in: R. Cont (ed.) Encyclopedia of Quantitative Finance, Vol. 4. John Wiley \& Sons, Chichester, 1867-1874. 


\section{Appendix}

\section{A The interest rate semi-elasticity of money demand}

Table A.1: The interest rate semi-elasticity of money demand in Switzerland.

\begin{tabular}{lrrr}
\hline $\boldsymbol{\tau}$ & $\hat{\boldsymbol{\beta}}$ & $\boldsymbol{S} . \mathrm{E}$. & $\boldsymbol{t}$-value \\
\hline Intercept & -0.00001 & 0.00007 & -0.18 \\
$\Delta r_{t}-\Delta r_{t}^{f}$ & 0.50986 & 1.47131 & 0.35 \\
\hline
\end{tabular}

Notes: The table displays the result of the regression $\Delta s_{t}=\psi+\alpha\left[\Delta r_{t}-\Delta r_{t}^{f}\right]+\eta t$, where $s_{t}$ denotes the log EUR-CHF exchange rate and both the home and the foreign risk-free interest rates $r$ and $r^{f}$, respectively, from September 06, 2011 to January 14, 2015. The vector $\hat{\beta}$ contains the estimated parameters $\hat{\psi}$ and $\hat{\alpha}$. Data source: Bloomberg.

\section{B Identities for the normal distribution function}

This appendix contains two identities that are used in this paper to obtain the main results. The identities correspond to Equations (A.1) and (A.2) in GERBER and PAfumi (2000) for $a=0$ and Equations (3.4) and (3.5) in Ko, Shiu, and WeI (2010):

$$
\int_{a}^{\infty} \exp ^{c . x} \cdot n\left(x ; \mu, \sigma^{2}\right) d x=\exp ^{\mu \cdot c+\frac{1}{2} \cdot \sigma^{2} \cdot c^{2}} \Phi\left(\frac{-a+\mu+\sigma^{2} \cdot c}{\sigma}\right)
$$

and

$$
\begin{aligned}
\int_{a}^{\infty} & \exp ^{c \cdot x} \cdot\left[1-\Phi\left(\frac{x-\mu}{\sigma}\right)\right] d x \\
= & -\frac{1}{c} \cdot \exp ^{a \cdot c} \cdot \Phi\left(\frac{-a+\mu}{\sigma}\right) \\
& +\frac{1}{c} \cdot \exp ^{\mu \cdot c+\frac{1}{2} \cdot \sigma^{2} \cdot c^{2}} \cdot \Phi\left(\frac{-a+\mu+\sigma^{2} \cdot c}{\sigma}\right) .
\end{aligned}
$$

In Equation (B.1), $a$ and $c$ are both arbitrary real numbers. Equation (C.2) requires the condition $c \neq 0$.

\section{The costs of a one-sided target zone under RGBM modeled as a call option}

In this section, it is first shown how the costs of enforcing a one-sided unilateral exchange rate target zone can be decomposed into the price of a call option 
when the underlying exchange rate follows a RGBM plus the implemented minimum exchange rate $b$, minus the value of one unit of foreign currency denominated in domestic currency units (i. e., $S_{t}$ ). Specifically, using a modification of Equation (11) in Veestraeten (2008) or Equation (15) in VeEstraeten (2013) and setting the strike price $X$ in these formulas equal to the minimum exchange rate $b$, the corresponding call option price (as of time $t$ ) then equals:

$$
\begin{aligned}
C_{r}\left(S_{t}, \tilde{T}\right) \equiv & C_{r}\left(b, r, r^{f}, \sigma, S_{t}, \tilde{T}\right) \\
= & S_{t} \exp ^{-r^{f} \tilde{T}} \Phi\left(z_{1}\right)-b \exp ^{-r \tilde{T}} \Phi\left(z_{1}-\sigma \sqrt{\tilde{T}}\right) \\
& +\frac{1}{\theta}\left\{S_{t} \exp ^{-r^{f} \tilde{T}}\left(\frac{b}{S_{t}}\right)^{1+\theta} \cdot \Phi\left(z_{2}\right)\right. \\
& \left.-b \exp ^{-r \tilde{T}} \Phi\left(z_{2}-\theta \sigma \sqrt{\tilde{T}}\right)\right\},
\end{aligned}
$$

with

$$
\begin{aligned}
& \theta=2 \frac{\mu^{\star}}{\sigma^{2}}, \\
& z_{1}=\frac{\ln \left(S_{t} / b\right)+\left(\mu^{\star}+\sigma^{2} / 2\right) \tilde{T}}{\sigma \sqrt{\tilde{T}}}, \\
& z_{2}=\frac{\ln \left(b / S_{t}\right)+\left(\mu^{\star}+\sigma^{2} / 2\right) \tilde{T}}{\sigma \sqrt{\tilde{T}}},
\end{aligned}
$$

where the subscript $r$ in $C_{r}\left(S_{t}, \tilde{T}\right)$ is included to distinguish the call option price under RGBM from its natural counterpart under GBM.

Lending $\left\{b \exp ^{-r T}\right\}$ units of the domestic currency plus the call option $C_{r}($.) ensures a payoff of $S_{T}$ at maturity date. Hence, the value of both equals the discounted expected value of $S_{T}$, which according to Equation 9 (using $S_{t}$ instead of $S_{0}$ ) equals:

$$
\exp ^{r f \tilde{T}}\left[C_{r}\left(S_{t}, \tilde{T}\right)+b \exp ^{-r \tilde{T}}\right]=\exp ^{\left(r^{f}-r\right) \tilde{T}} E^{Q^{R G B M}}\left(S_{T}\right)=V\left(S_{t}, \tilde{T}\right)+S_{t}
$$

\section{The maximum possible costs of a one-sided target zone under RGBM}

In this section, the condition that implies an upper bound for the costs of enforcing a unilateral one-sided exchange rate target zone $V\left(S_{t}, \tilde{T}\right)$ is derived. Taking the derivative of Equation C.2 with respect to $S_{t}$ and using the derivative of a standard call option under GBM with respect to $S_{t}$ gives: 


$$
\begin{aligned}
\frac{\partial V\left(S_{t}, \tilde{T}\right)}{\partial S_{t}} & =\frac{\partial C_{r}\left(S_{t}, \tilde{T}\right)}{\partial S_{t}}-1 \\
& =\frac{\partial C_{r}\left(S_{t}, \tilde{T}\right)}{\partial S_{t}}-\left[\frac{\partial C\left(S_{t}, \tilde{T}\right)}{\partial S_{t}}+\Phi\left(-z_{1}\right)\right]<0,
\end{aligned}
$$

since $\frac{\partial C_{r}\left(S_{t}, \tilde{T}\right)}{\partial S_{t}} \leq \frac{\partial C\left(S_{t}, \tilde{T}\right)}{\partial S_{t}}$ (VEEstraeten, 2013).

\section{E Additional figures}

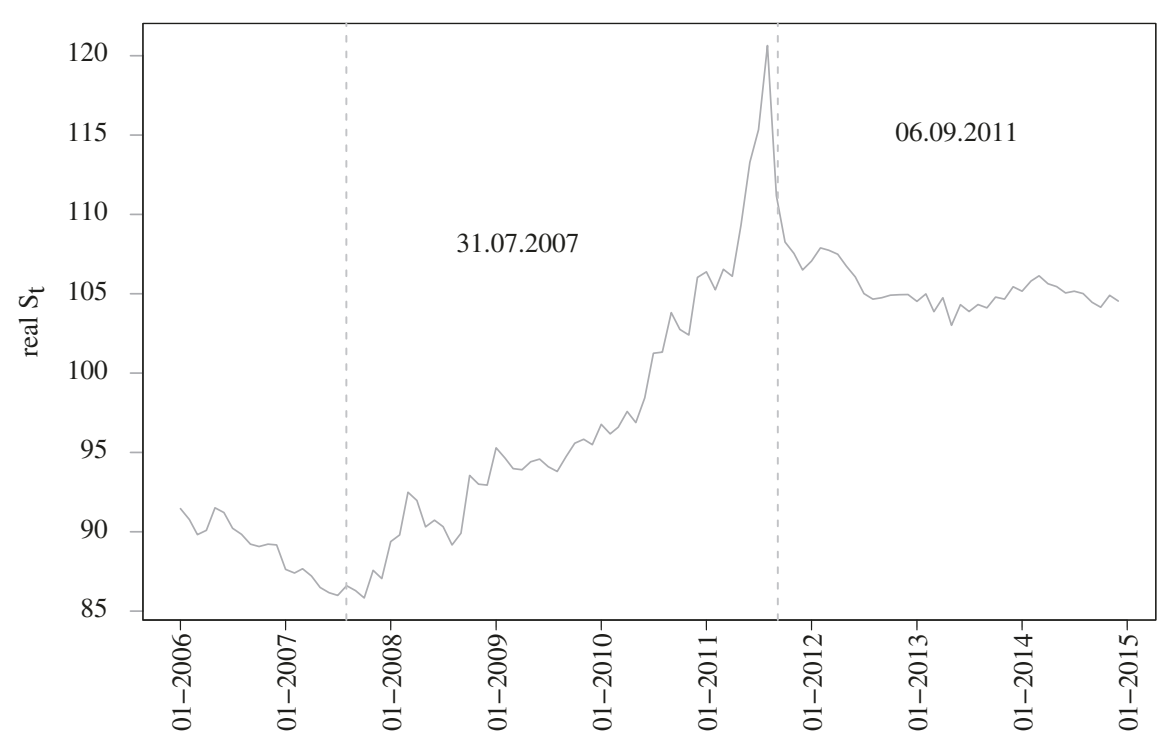

Figure E.1: Real effective CHF exchange rate.

Notes: The figure plots the monthly real effective CHF exchange rate from January 01, 2006 to December 31, 2014. The first marked date (31.07.2007) refers to the date when the recent financial crisis erupted in summer 2007, announcement of the "Draghi put" ("Whatever it takes"), the second marked date (06.09.2011) to the date when the Swiss National Bank announced the EUR-CHF 1.20 floor. Data source: Bank for International Settlements. 


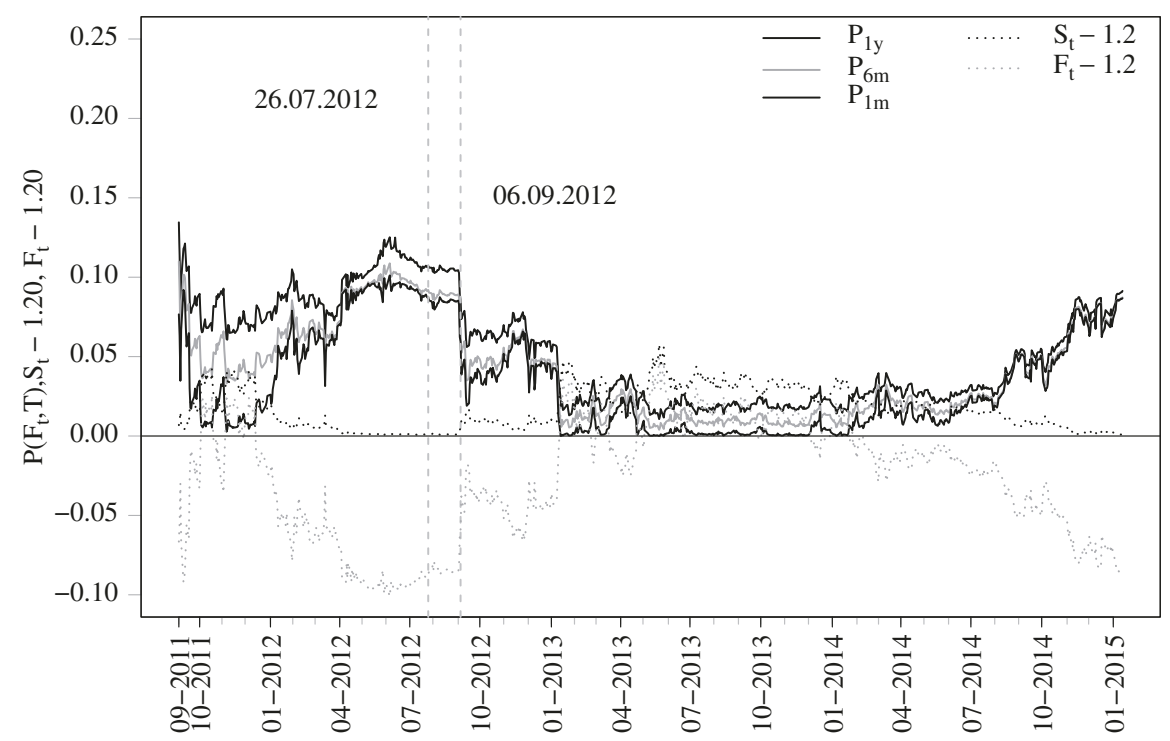

Figure E.2: Target zone costs writing put options (Model 2).

Notes: The figure shows the costs (in $\mathrm{CHF}$ ) of implementing a one-sided target zone for a lifetime of 1 month $\left(P_{1 m}\right), 6$ months $\left(P_{6 m}\right)$ or 1 year $\left.P_{1 y}\right)$, respectively, under the assumptions of model 2 from September 6, 2011 to January 14, 2015. The first marked date (26.07.2012) refers to the announcement of the "Draghi put" ("Whatever it takes"), the second marked date (06.09.2012) to the date when the European Central Bank launched the Outright Monetary Transaction (OMT) program. The dotted line displays the deviation of the FX rate $\tilde{S}_{t}$ from the EUR-CHF 1.20 floor. Data source: Bloomberg. 


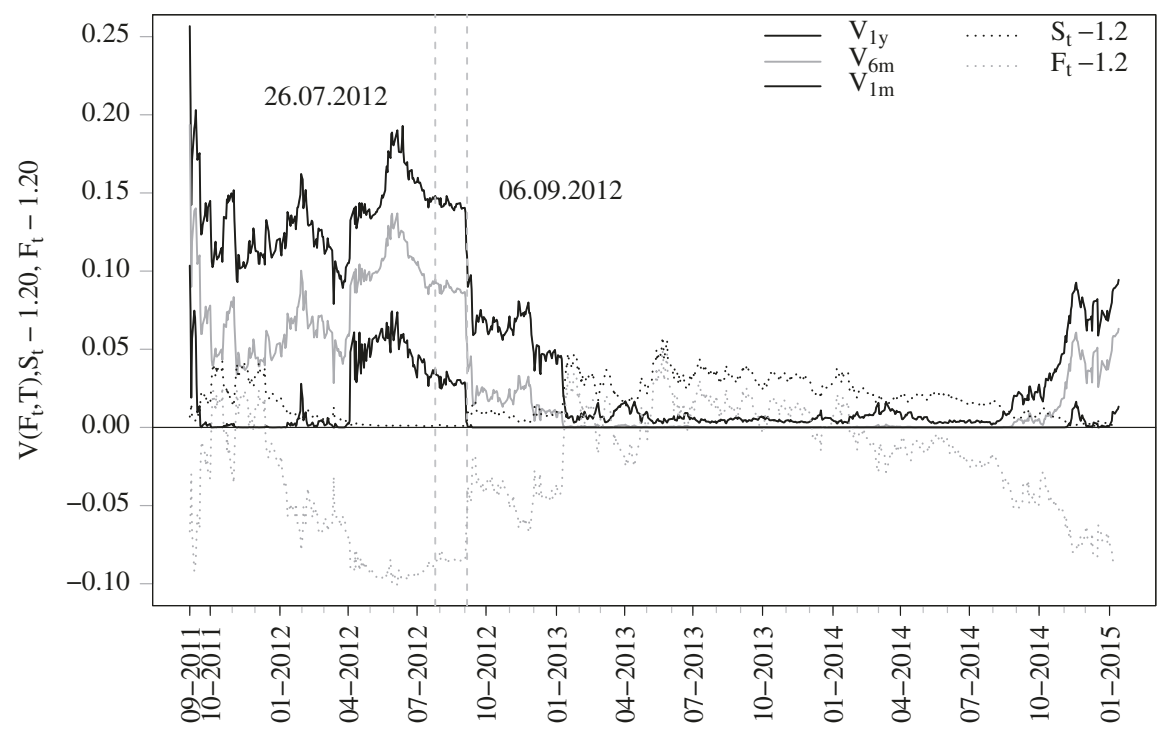

Figure E.3: Target zone costs under RGBM based on the latent EUR-CHF FX rate (Model 3). Notes: The figure shows the costs (in CHF) of implementing a one-sided target zone for a lifetime of 1 month $\left(V_{1 m}\right), 6$ months $\left(V_{6 m}\right)$ or 1 year $\left(V_{1 y}\right)$, respectively, under the assumptions of model 3 from September 6, 2011 to January 14, 2015. The first marked date (26.07.2012) refers to the announcement of the "Draghi put" ("Whatever it takes"), the second marked date (06.09.2012) to the date when the European Central Bank launched the Outright Monetary Transaction (OMT) program. The dotted line displays the deviation of the FX rate $\tilde{S}_{t}$ from the EUR-CHF 1.20 floor. Data source: Bloomberg. 